\title{
Regulation of Overnutrition-Induced Cardiac Inflammatory Mechanisms by Nebivolol
}

\author{
Rukhsana Gul ${ }^{a}$, d, e Vincent G. DeMarco ${ }^{a, c, d}$ James R. Sowers ${ }^{a, c-e}$ \\ Adam Whaley-Connell ${ }^{\text {a, }}$, e Lakshmi Pulakat $^{a}$, b, d, e \\ Departments of ${ }^{\mathrm{a}}$ Internal Medicine, ${ }^{\mathrm{b}}$ Nutrition and Exercise Physiology, ${ }^{\mathrm{C}}$ Medical \\ Pharmacology and Physiology, and ${ }^{\mathrm{d}}$ Diabetes and Cardiovascular Laboratory, and \\ eHarry S. Truman Veterans Affair Medical Center, University of Missouri School of Medicine, \\ Columbia, Mo., USA
}

\section{Key Words}

Nebivolol $\cdot$ Zucker obese $\cdot$ AMP kinase $\cdot$ mTORC1 $\cdot$ Jak/STAT

\begin{abstract}
Background: Unlike conventional $\beta$-blockers, nebivolol, a third-generation $\beta$-adrenergic receptor blocker with vasodilator properties, promotes insulin sensitivity. Objective: The objective of this study was to determine whether nebivolol regulates overnutrition-induced activation of cardiac nutrient sensor kinases and inflammatory signaling. Methods: Young Zucker obese (ZO) rats, a rodent model for overnutrition, and age-matched Zucker lean rats were treated with nebivolol (10 mg/kg/day; 21 days) and cardiac function was monitored by echocardiography and pressure volume loop analysis. Activation status of nutrient sensor serine/threonine kinases mammalian target for rapamycin (mTOR), and p70 S6kinase (S6K1) and S6K1-substrate RPS6, inflammatory marker Janus kinase 2 (Jak2) and its substrate STAT1, and energy sensor AMP-dependent kinase (AMPK) were monitored by determining phosphorylation status of $\mathrm{pSer}^{2448}$ of mTOR, pThr ${ }^{389}$ of S6K1, pSer ${ }^{235 / 236}$ of RPS6, pTyr ${ }^{1007 / 1008}$ of Jak2, pTyr ${ }^{701}$ of STAT1, and pThr ${ }^{172}$ of AMPK, respectively. Results: Nebivolol reduced weight and improved cardiac function of ZO rats as shown by improvements in the myocardial performance index and a decrease in the diastolic parameter tau $(\tau)$, the time constant of isovolumic relaxation. Nebivolol also attenuated excessive activation of the nutrient sensor kinases mTOR and S6K1 and their substrate
\end{abstract}




\section{CardioRenal Medicine}

\begin{tabular}{l|l}
\hline Cardiorenal Med 2012;2:225-233 \\
\hline $\begin{array}{l}\text { DOI: 10.1159/000339565 } \\
\text { Published online: July 24, 2012 }\end{array}$ & $\begin{array}{l}\text { ○ } 2012 \text { S. Karger AG, Basel } \\
\text { www.karger.com/crm }\end{array}$ \\
\hline $\begin{array}{l}\text { Gul et al.: Regulation of Overnutrition-Induced Cardiac Inflammatory Mechanisms by } \\
\text { Nebivolol }\end{array}$
\end{tabular}

RPS6 as well as the inflammatory marker Jak2 and substrate STAT1 in ZO myocardium $(p<0.05)$. Moreover, nebivolol reversed suppression of the energy sensor kinase AMPK in ZO hearts $(p<$ 0.05). Conclusion: We report for the first time that nebivolol regulates overnutrition-induced activation of cardiac mTOR and Jak/STAT signaling and reverses suppression of AMPK. Since it also suppresses weight gain, nebivolol appears effective in the treatment of overnutrition-related cardiac inflammation and diastolic dysfunction.

Copyright $\odot 2012$ S. Karger AG, Basel

\section{Introduction}

In conditions of obesity and the cardiorenal metabolic syndrome (CRS), a complex interplay between nutrients, the $\beta$-adrenergic receptor ( $\beta$-AR) signaling pathway, the reninangiotensin system, and insulin metabolic signaling underlies progression of cardiorenal pathology. Data emerging from randomized clinical trials and subsequent meta-analyses indicate that conventional $\beta 1$ adrenergic receptor ( $\beta 1-\mathrm{AR})$ blockers have a propensity to increase weight and promote an increased incidence of new-onset diabetes [1-3]. In this context, nebivolol is a third-generation $\beta 1$-AR blocker that is structurally different from previous $\beta$-blockers and possesses the highest selectivity for $\beta 1$-AR (up to 320 -fold vs. $\beta 2$-AR). Further, nebivolol is unique in that it activates endothelial nitric oxide synthase (eNOS) and promotes vasodilatation $[4,5]$. We and others reported that nebivolol improves cardiac and renal protection in both rodent models and patients with hypertension and insulin resistance [6-10]. These beneficial effects of nebivolol are attributable to nebivolol-mediated dose-dependent nitric oxide $(\mathrm{NO})$ production that can promote vasodilatation and improve insulin sensitivity. However, it remains unclear if nebivolol attenuates overnutrition-associated excessive activation of cardiac nutrient sensor kinases and inflammatory signaling and promotes cardiac health in conditions of overnutrition.

Nebivolol induces dose-dependent NO production, an action that is not inhibited by other $\beta 1$-AR blockers, but attenuated by the $\beta 3$-AR antagonist SR59230A [11-13]. Therefore, $\beta 3$-AR-induced myocardial NOS upregulation and NO bioavailability underlies the beneficial pleiotropic effects of nebivolol in the heart. In this regard, the cardioprotective serine (Ser) kinase AMP activated kinase (AMPK) that serves as an energy sensor phosphorylates Ser633 of eNOS and activates eNOS [14], is a potential target of nebivolol. A recent report suggests that AMPK serves as a mediator for the $\beta 3$-AR agonist BRL-37344-induced NO production [15]. However, AMPK-mediated phosphorylation of the scaffolding protein Raptor and tubular sclerosis complex 2 (TSC2) inhibits the formation of the nutrient sensor kinase mTOR complex 1 (mTORC1) and subsequent phosphorylation of p70 S6 kinase (S6K1). We showed that nebivolol treatment activated AMPK in the transgenic mRen2 rat heart [6]. In conditions of overnutrition, mTORC1/S6K1 activation acts as a nexus for converging signaling from nutrients, cytokines, insulin and angiotensin II, and becomes excessively activated in cardiovascular tissues and this likely contributes to structural and functional abnormalities $[16,17]$. Activated S6K1 induces inhibitory phosphorylation of Ser residues in insulin receptor substrate 1 (IRS-1) and thus attenuates normal insulin metabolic signaling. It is conceivable that if nebivolol can activate AMPK, it would attenuate mTORC1/S6K1 signaling in the heart. Thereby, we posited that in addition to activating eNOS and promoting vasodilatation, nebivolol would modulate nutrient sensor kinases (mTOR/S6K1).

In the heart, pro-apoptotic pathways are activated by the signal transducer and activator of transcription-1 (STAT1)-dependent pathway [18]. Janus kinase 2 (Jak2), the inflammatory tyrosine (Tyr) kinase that phosphorylates $\mathrm{pTyr}^{701}$ of STAT1, is the upstream activator of STAT1. Interestingly, studies show that mTOR also can regulate STAT1 [19]. Since overnutri- 


\section{CardioRenal Medicine}

\begin{tabular}{l|l}
\hline Cardiorenal Med 2012;2:225-233 \\
\hline DOI: 10.1159/000339565 & $\begin{array}{l}\text { @ 2012 S. Karger AG, Basel } \\
\text { www.karger.com/crm }\end{array}$ \\
\hline Published online: July 24, 2012 &
\end{tabular}

Gul et al.: Regulation of Overnutrition-Induced Cardiac Inflammatory Mechanisms by Nebivolol

tion can activate both mTOR and Jak2, we posited that STAT1 would be activated in cardiac tissue under conditions of overnutrition and nebivolol would attenuate STAT1 activation. This investigation was undertaken to determine whether nebivolol attenuates overnutritioninduced excess activation of cardiac nutrient sensor kinases (mTOR/S6K1) and inflammatory signaling via Jak2/STAT1 and promotes activation of energy sensor kinase AMPK in Zucker obese (ZO) rats. We further posited that nebivolol would improve diastolic function in this rodent model for obesity that exhibits characteristics of the CRS.

\section{Methods}

\section{Animal Studies}

All animal procedures were approved in advance by the Harry S. Truman Veterans Memorial Hospital Subcommittee for Animal Safety, as well as by the University of Missouri IACUC, and animals were cared for in accordance with Guidelines for the Care and Use of Laboratory Animals (National Institutes of Health publication 85-23). Male Zucker lean (ZL) control and ZO rats (9-12 weeks old) were purchased from Charles River Laboratories (Saint-Constant, Que., Canada) and housed under standard laboratory conditions where room temperature was $21-22^{\circ} \mathrm{C}$ and light and dark cycles were $12 \mathrm{~h}$ each. Animals were divided into four groups: vehicle treated (ZOC and ZLC; $\mathrm{n}=6 \mathrm{each}$ ) or nebivolol treated (ZON and ZLN; $\mathrm{n}=6$ each), respectively. ZON and ZLN animals were treated with nebivolol $10 \mathrm{mg} / \mathrm{kg} / \mathrm{day}$ released via an implanted osmotic mini-pump for 21 days as described previously $[7,9]$.

\section{Echocardiography and Pressure Volume Loop Analysis}

Transthoracic echocardiography (echo), including Doppler examination, was performed on isoflurane anesthetized rats (4\% induction and $1.75 \%$ maintenance) using a GE Vivid i ultrasound system with a $10.5-\mathrm{MHz}$ phased-array pediatric probe (10S). Echo examinations were performed while rats were in the left lateral decubitus position as explained previously [16]. All parameters were assessed by using an average of three beats, and calculations were made in accordance with published guidelines for echocardiographic studies in rodents [16, 20]. Cardiac pressure volume (PV) loop analysis was performed by PV loop system (Scisense, Inc., Ont., Canada) employing direct catheterization of the left ventricle which yields several load-independent indices of diastolic and systolic function, as we have reported previously $[16,21]$.

\section{Immunoblotting}

Left ventricular (LV) lysates from different treatments (40-60 $\mu \mathrm{g} / \mathrm{lane})$ were separated and transferred to polyvinylidene difluoride (PVDF) membranes (Bio-Rad Laboratories). All antibodies were from Cell Signaling Technology Inc. (Boston, Mass., USA). Immunoblotting was performed as described previously $[6,21]$.

\section{Statistics}

Values are expressed as means \pm SE. Statistical comparisons were performed with Sigma Stat (Aspire Software Intl., Ashburn, Va., USA) using ANOVA followed by the Scheffe's test. A value of $\mathrm{p}<0.05$ was considered to be significant.

\section{Results}

\section{Nebivolol Suppressed Weight Gain and Improved Cardiac Functions in the ZO Heart}

$\mathrm{ZO}$ rats have a mutation in the leptin receptor and are hyperphagic and hyperinsulinemic. They exhibited significantly higher body weight at the age of 12 weeks than agematched ZL controls, and this weight gain was suppressed by nebivolol (fig. 1a; $p=0.05$ ). It has been shown that $\mathrm{ZO}$ rats develop obesity-related diastolic and systolic dysfunction [9]. The myocardial performance index (MPI), an echocardiographic index of global cardiac 


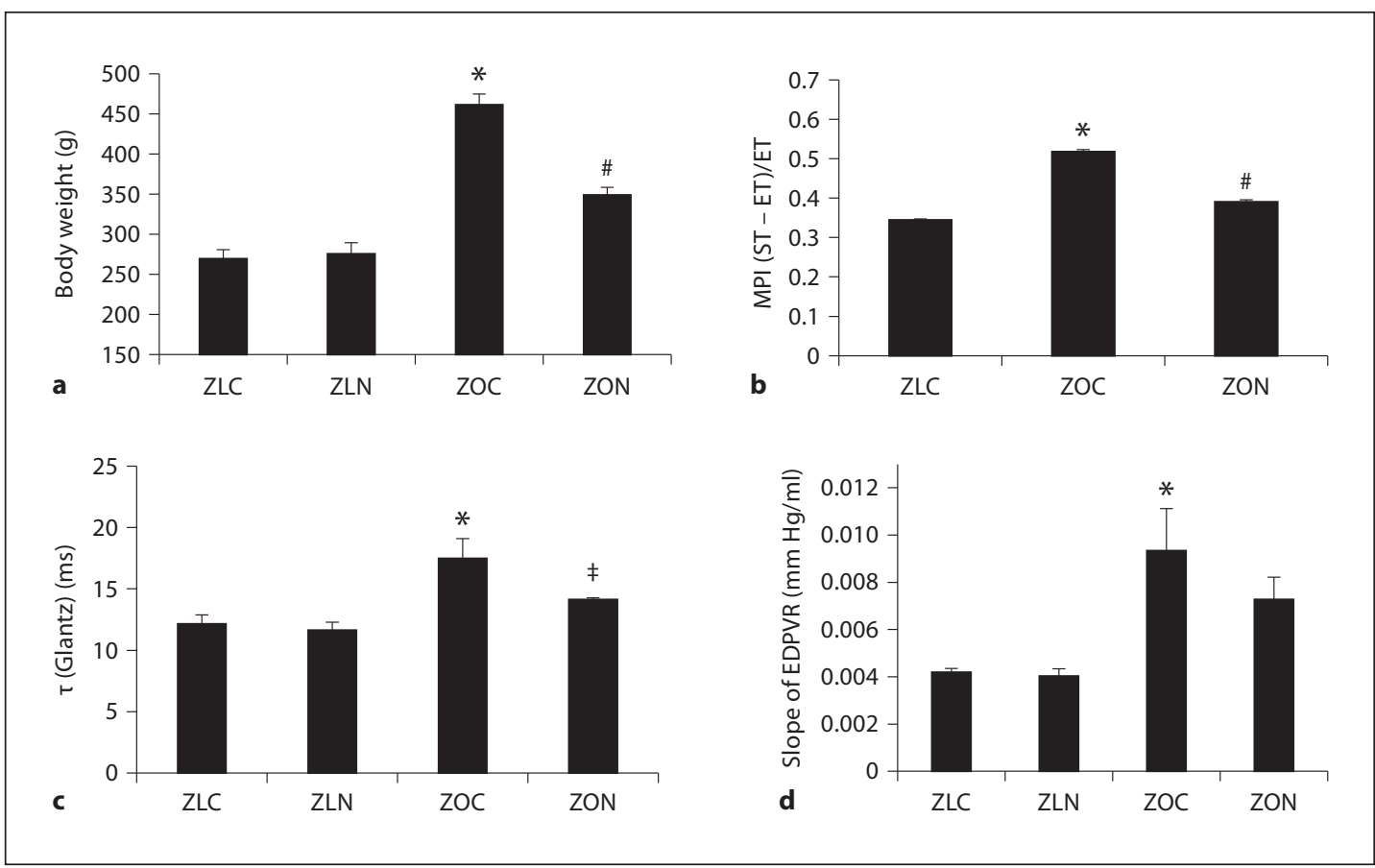

Fig. 1. Nebivolol suppressed weight gain and improved cardiac function parameters in $Z O$ rats. a Body weight of $\mathrm{ZO}$ and $\mathrm{ZL}$ rats with and without nebivolol treatment. ZLC = Untreated ZL rat; ZOC = untreated ZO rat; ZLN = ZL rat treated with nebivolol; $Z O N=Z O$ rat treated with nebivolol; * $\mathrm{p}<0.05$ vs. ZLC; \# $\mathrm{p}<0.05$ vs. ZOC. b Echocardiographic analysis showed MPI was improved (MPI is decreased) in ZO rats treated with nebivolol. c, d PV loop analysis showed that nebivolol partially reversed the changes in tau $(\tau)$ (Glantz) and EDPVR in ZOC rats. ${ }^{*} \mathrm{p}<0.05$ vs. ZLC; ${ }^{*} \mathrm{p}<0.05$ vs. ZOC; ${ }^{\ddagger} \mathrm{p}=0.06$ vs. ZOC. Results are expressed as mean \pm SEM of 4 rats per experimental group. ST $=$ Systolic time; ET $=$ ejection time.

function, tau $(\tau)$, the time constant of isovolumic relaxation and an index of the active component of early diastolic relaxation, and the slope of the end-diastolic pressure volume relationship (EDPVR), a marker of LV wall stiffness, were all significantly elevated in 12-weekold $\mathrm{ZO}$ rats compared to ZL rats $(\mathrm{p}<0.05$; fig. $1 \mathrm{~b}-\mathrm{d})$ indicating impaired diastolic function in $\mathrm{ZO}$ rats. Nebivolol treatment normalized MPI (fig. $1 \mathrm{~b}, \mathrm{ZO}$ vs. $\mathrm{ZON} ; \mathrm{p}<0.05)$ and $\tau(\mathrm{p}=$ 0.06 ), but did not significantly reduce EDPVR ( $p>0.05)$. These observations support the concept that nebivolol results in modest attenuation of overnutrition-associated weight gain and cardiac dysfunction in 12-week-old ZO rats.

\section{Nebivolol Attenuated Overnutrition-Associated Activation of mTOR-S6K1-RPS6}

Signaling in the Myocardium of 12-Week-Old ZO Rat Hearts

We observed significant reductions in total protein levels of mTOR and S6K1 in LV lysates of ZO rats compared to ZL rats; however, the ratios of phosphoprotein (mTORpSer ${ }^{2448}$, S6K1pThr ${ }^{389}$, and RPS6pSer ${ }^{235 / 236}$ ) to total protein were significantly higher in ZO LV lysates compared to ZL LV lysates (fig. 2a-c). Nebivolol treatment restored the ratios of phosphoprotein to total protein for mTOR, S6K1, and RPS6 (fig. 2a-c). To our knowledge, this is the first report that shows that nebivolol regulates overnutrition-related mTORC1 activation. 


\section{CardioRenal Medicine}
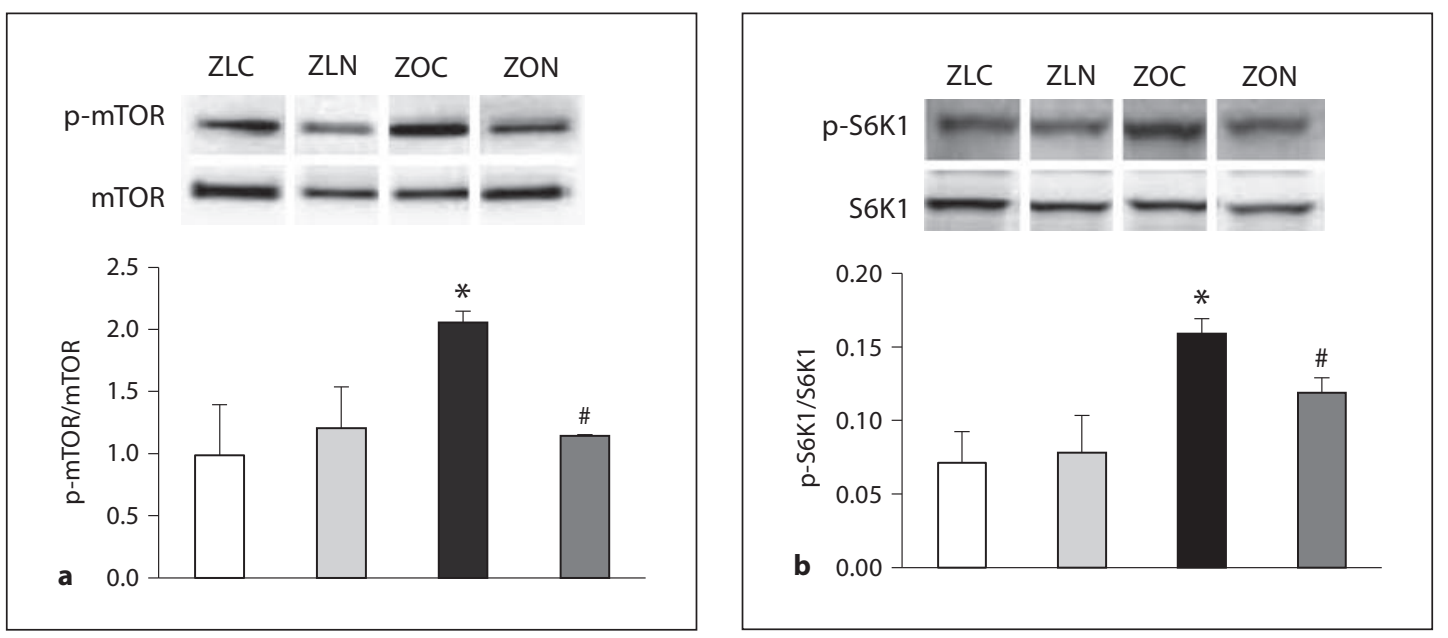

Fig. 2. Nebivolol suppressed excessive activation of nutrient sensor kinases in $\mathrm{ZO}$ myocardium. Levels of $\mathrm{pSer}^{2448}$ mTOR (p-mTOR) (a), pThr ${ }^{389}$ S6k1 (pS6K1) (b), and pSer ${ }^{235 / 236}$ RPS6 (p-RPS6) (c) were elevated in ZOC LV lysates, and nebivolol attenuated these effects. ${ }^{*} \mathrm{p}<0.05$ vs. control; ${ }^{\#} \mathrm{p}<0.05$ vs. Ang II. Results are expressed as mean \pm SEM of 4 rats per experimental group.

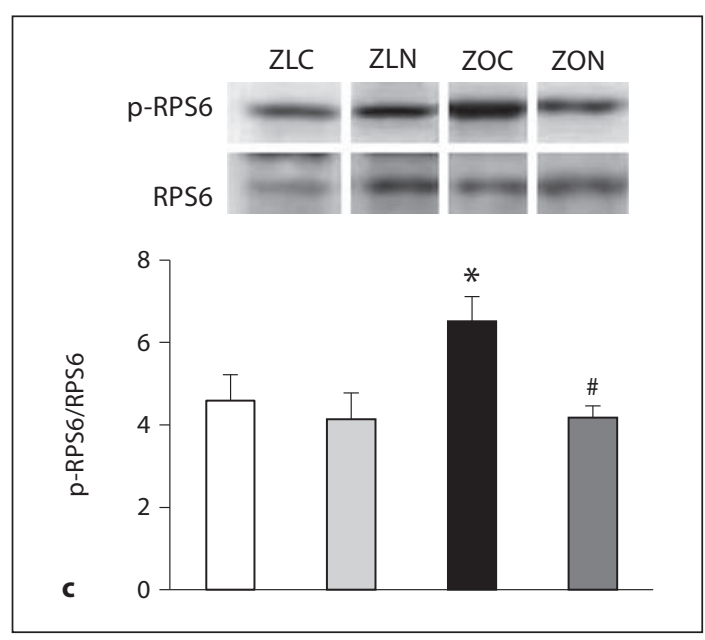

Nebivolol Enhanced Stimulatory Phosphorylation of AMPK in the Myocardium of 12-Week-Old ZO Rat Hearts

Previous studies demonstrated that AMPK, an energy sensor/metabolic switch [14, 22], responds to energy stress by suppressing cell growth and biosynthetic processes, in part through its inhibition of mTORC1. Since nebivolol attenuated mTORC1 activation, we tested if nebivolol activates AMPK in the myocardium and HL-1 cardiomyocytes. Moreover, $\beta 3-\mathrm{AR}$ agonists (such as nebivolol) activate eNOS and increase NO production, in part, via AMPK activation [15]. We observed a significant decrease in $\mathrm{pThr}^{172} \mathrm{AMPK}$ in LV lysates of $\mathrm{ZO}$ rats, and this effect was reversed in nebivolol-treated $\mathrm{ZO}$ rats (fig. 3). This observation is consistent with nebivolol's ability to activate $\beta 3$-AR that signals through AMPK.

Nebivolol Attenuated Stimulatory Phosphorylation of Tyr Kinase Jak2 and Its Substrate

STAT1 in the Myocardium of 12-Week-Old ZO Rat Hearts

In conditions of overnutrition, many factors (hyperinsulinemia, activation of the reninangiotensin-aldosterone system, oxidative stress, and other cytokines) can activate Jak2, an inflammatory kinase implicated in hypertension and ischemic injury [23]. While Jak2 activates STAT1 by phosphorylation of $\mathrm{Tyr}^{701}$, mTOR is implicated in associating with STAT1 


\section{CardioRenal Medicine}

\begin{tabular}{l|l}
\hline Cardiorenal Med 2012;2:225-233 \\
\hline DOI: $10.1159 / 000339565$ \\
Published online: July 24, 2012 & $\begin{array}{l}\text { @ 2012 S. Karger AG, Basel } \\
\text { www.karger.com/crm }\end{array}$ \\
\hline
\end{tabular}

Gul et al.: Regulation of Overnutrition-Induced Cardiac Inflammatory Mechanisms by Nebivolol

Fig. 3. Nebivolol enhanced AMPK phosphorylation in $\mathrm{ZO}$ myocardium. Level of pThr ${ }^{172}$ AMPK was reduced in $\mathrm{ZO}$ rats, and nebivolol reversed this effect. * $\mathrm{p}<0.05$ vs. ZLC; ${ }^{\# \#} \mathrm{p}<0.01$ vs. ZOC. Results are expressed as mean \pm SEM of 4 rats per experimental group.
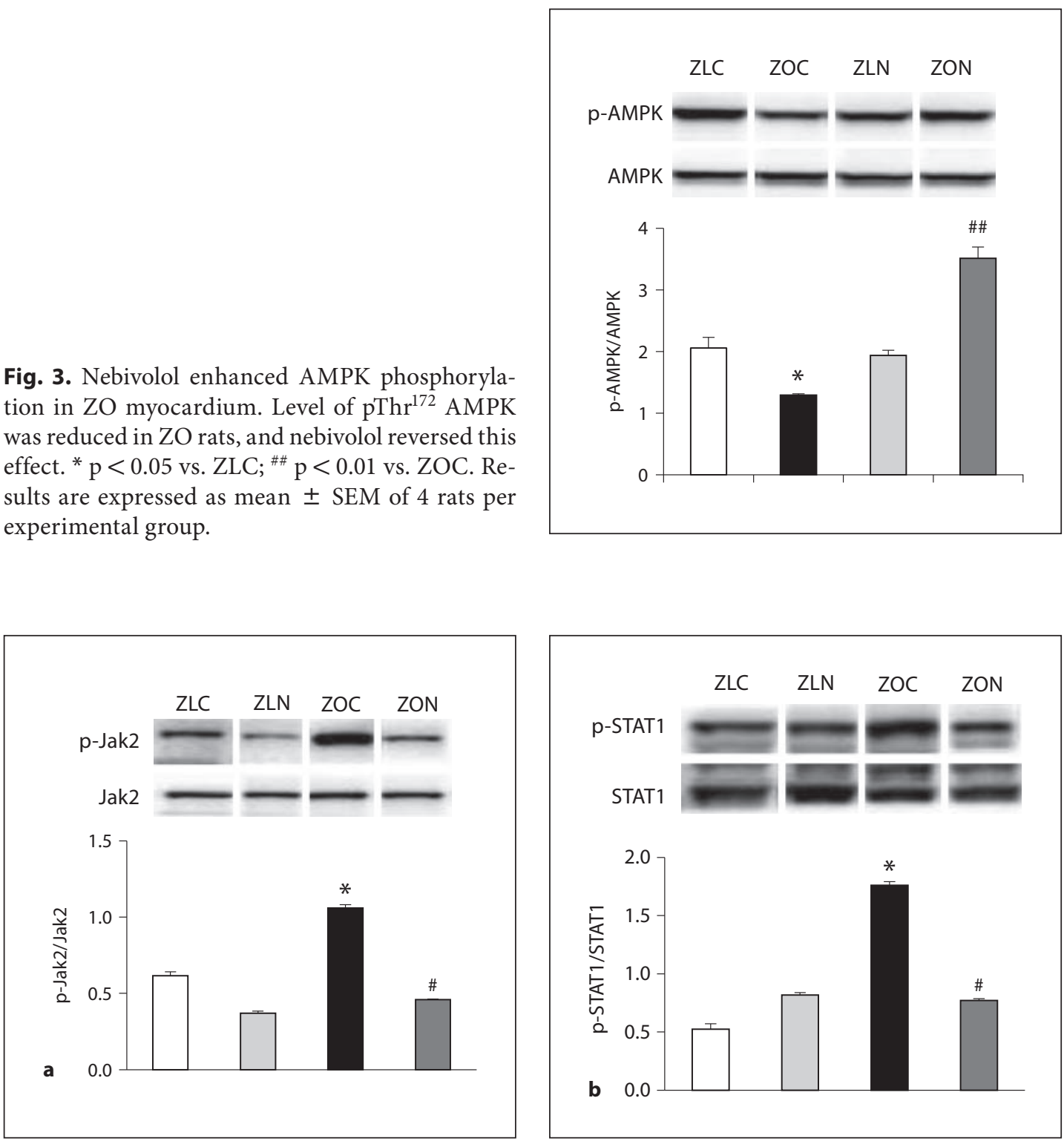

Fig. 4. Nebivolol attenuated activation of inflammatory, pro-apoptotic Jak2/STAT1 signaling in ZO myocardium. Levels of pTyr ${ }^{1007 / 1008}$ Jak2 (a) and pTyr ${ }^{701}$ STAT1 (b) were elevated in ZOC LV lysates, and nebivolol attenuated these effects. ${ }^{*} \mathrm{p}<0.05$ vs. ZLC; ${ }^{*} \mathrm{p}<0.05$ vs. Ang II. Results are expressed as mean \pm SEM of 4 rats per experimental group.

and increasing STAT1-dependent gene expression [19]. Therefore, we tested if Jak2 and STAT1 are activated in cardiac tissues of hyperinsulinemic, insulin-resistant obese ZO rats and whether their activation is suppressed by nebivolol. Significant increases in phosphorylation of Tyr ${ }^{1007 / 1008}$ of Jak2 and $\mathrm{Tyr}^{701}$ of STAT1 were observed in ZO LV lysates compared to those of ZL (fig. 4a, b). Nebivolol treatment significantly reduced stimulatory phosphorylation of both Jak2 and STAT1. This is the first report that shows activation of the Jak2/ STAT1 pathway in cardiac tissues of the obese, insulin-resistant ZO rat and that nebivolol attenuates this inflammatory signaling. 


\section{CardioRenal Medicine}

\begin{tabular}{l|l}
\hline \multicolumn{2}{l}{ Cardiorenal Med 2012;2:225-233 } \\
\hline $\begin{array}{l}\text { DOI: 10.1159/000339565 } \\
\text { Published online: July 24, 2012 }\end{array}$ & $\begin{array}{l}\text { ○ } 2012 \text { S. Karger AG, Basel } \\
\text { www.karger.com/crm }\end{array}$ \\
\hline $\begin{array}{l}\text { Gul et al.: Regulation of Overnutrition-Induced Cardiac Inflammatory Mechanisms by } \\
\text { Nebivolol }\end{array}$
\end{tabular}

\section{Discussion}

Nebivolol is a third-generation $\beta 1$-adrenoceptor antagonist approved for treatment of hypertension and heart failure. In this context, we previously showed that nebivolol improved insulin sensitivity, myocardial ultrastructure, and diastolic function, as well as reduced myocardial fibrosis and weight gain in younger (9-week-old) ZO rats [9]. This study confirms the efficacy of nebivolol in an older cohort of $\mathrm{ZO}$ rats and extends those results by demonstrating that nebivolol possesses novel pleiotropic effects that confer cardioprotection by blunting the excessive pro-growth and pro-inflammatory signaling that occurs in the setting of obesity.

Previous studies demonstrate that mTORC1 inhibition by rapamycin suppresses myocardial hypertrophy $[24,25]$. Moreover, endogenous mTOR expression is significantly elevated in patients with advanced heart failure and in mice with pathological hypertrophy and cardiac dysfunction [25]. Activation of mTORC1 signaling leads to insulin resistance in high fat-fed obese rats [26]. In addition, studies with S6K1 knockout mice demonstrate that S6K1 plays a central role in the development of obesity and insulin resistance [27]. Consistent with these studies, our data show increases in phosphorylation of mTOR $\left(\mathrm{pSer}^{2448}\right)$, S6K1 $\left(\mathrm{pThr}^{389}\right)$, and RPS6 ( $\mathrm{p} \mathrm{Ser}{ }^{235 / 236}$ ) in ZO myocardium, all of which were significantly reduced by nebivolol treatment. Because mTORC1 activation impairs insulin-stimulated vasodilatation by inhibiting eNOS activation [28], we posit that the nebivolol-mediated increase in eNOS activation and increased vasodilation in $\mathrm{ZO}$ rats may be partly due to its inhibitory effect on the mTORC1 signaling pathway.

Another salient point emerging from this study is that nebivolol activates the energy sensor AMPK (fig. 3) in concert with improvements in LV function. AMPK, a stress-activated protein kinase, plays a cardioprotective role by improving LV function and cardiomyocyte survival in heart failure [29, 30]. Deficiency in AMPK exacerbates cardiac hypertrophy and contractile dysfunction [31]. AMPK enhances eNOS activity by direct phosphorylation at Ser1177 and increases the production of endothelium-derived NO. Consistent with our results from transgenic Ren2 rats [6], we observed a decrease in phosphorylation of AMPK $\left(\mathrm{pThr}^{172}\right)$ in ZO myocardium, which was significantly enhanced by nebivolol treatment. The ability of nebivolol to activate AMPK in ZO myocardium is also consistent with the concept that nebivolol can promote $\beta 3$-AR agonism that leads to AMPK activation and subsequent eNOS activation.

Activation of the Jak/STAT pathway is implicated in promoting cardiac inflammation $[18,19]$. The observation that nebivolol, a $\beta 3$-AR agonist, suppresses cardiac Jak 2 and STAT 1 in the $\mathrm{ZO}$ rat is also surprising. It was reported previously that activation of $\beta 3$-AR stimulates Jak2/STAT1 signaling in adipocytes [32]. Therefore, it is conceivable that nebivololmediated inhibition of inflammatory and pro-apoptotic Jak2/STAT1 pathway might not be mediated via $\beta 3-\mathrm{AR}$. To this point, it should be noted that, in fact, leptin is an activator of Jak2. Further studies are required to decipher how nebivolol suppresses cardiac Jak2/STAT1 signaling in the leptin-resistant $\mathrm{ZO}$ rat.

Emerging evidence strongly supports the notion that diet-induced obesity can lead to leptin resistance, whereas leptin resistance predisposes individuals to hyperphagia which further exacerbates diet-induced obesity and CRS [33]. In this context, the ZO rat serves as an interesting model since its obesity is a result of its leptin resistance. Data presented here suggest that nebivolol can help to overcome this vicious cycle leading to weight gain by a leptin-independent mechanism since a 3-week nebivolol treatment significantly reduced weight gain (fig. 1a) and improved cardiac function (fig. 1b-d) in a leptin-resistant animal (ZO rat). 


\section{CardioRenal Medicine}

\begin{tabular}{l|l}
\hline Cardiorenal Med 2012;2:225-233 \\
\hline DOI: $10.1159 / 000339565$ \\
Published online: July 24, 2012 & $\begin{array}{l}\text { ( ) 2012 S. Karger AG, Basel } \\
\text { www.karger.com/crm }\end{array}$ \\
\hline
\end{tabular}

Gul et al.: Regulation of Overnutrition-Induced Cardiac Inflammatory Mechanisms by Nebivolol

In conclusion, data presented here demonstrate that nebivolol regulates overnutritioninduced activation of cardiac MTOR and Jak/STAT signaling and reverses suppression of AMPK. Moreover, nebivolol also suppresses weight gain by a leptin-independent mechanism and improves cardiac function. These novel pleotropic effects of nebivolol imply that nebivolol could be an effective cardioprotective drug in conditions of overnutrition and leptin resistance.

\section{Acknowledgements}

This work was supported by University of Missouri Mission Enhancement Fund (L.P.), the Forest Research Institute grant (L.P.) and NIH (R01 HL73101-08 and R01 HL107910-03) (J.R.S.) and Veterans Affairs Merit System 0018 (J.R.S.). We thank N. Rehmer, M. Garro, R. Schneider, and S. Arnold for their technical support and B. Hunter for editorial assistance.

\section{Disclosure Statement}

The authors declare that they have no conflicts of interest.

\section{References}

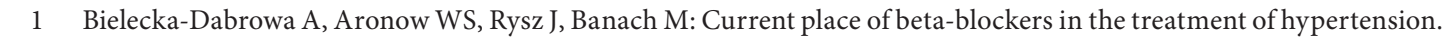
Curr Vasc Pharmacol 2010;8:733-741.

-2 Bangalore S, Wild D, Parkar S, Kukin M, Messerli FH: Beta-blockers for primary prevention of heart failure in patients with hypertension: insights from a meta-analysis. J Am Coll Cardiol 2008;52:1062-1072.

-3 Law MR, Morris JK, Wald NJ: Use of blood pressure lowering drugs in the prevention of cardiovascular disease: metaanalysis of 147 randomized trials in the context of expectations from prospective epidemiological studies. BMJ 2009; 338:b1665.

4 Münzel T, Gori T: Nebivolol: the somewhat-different beta-adrenergic receptor blocker. J Am Coll Cardiol 2009;54: 1491-1499.

5 Gupta S, Wright HM: Nebivolol: a highly selective beta1-adrenergic receptor blocker that causes vasodilation by increasing nitric oxide. Cardiovasc Ther 2008;26:189-202.

6 Ma L, Gul R, Habibi J, Yang M, Pulakat L, Whaley-Connell AT, Ferrario CM, Sowers JR: Nebivolol improves diastolic dysfunction and myocardial remodeling through reductions in oxidative stress in the transgenic (mRen2) rat. Am J Physiol Heart Circ Physiol 2012, E-pub ahead of print.

7 Habibi J, Hayden MR, Sowers JR, Pulakat L, Tilmon RD, Manrique C, Lastra G, Demarco VG, Whaley-Connell A: Nebivolol attenuates redox-sensitive glomerular and tubular mediated proteinuria in obese rats. Endocrinology 2011; 152:659-668.

8 Manrique C, Lastra G, Habibi J, Pulakat L, Schneider R, Durante W, Tilmon R, Rehmer J, Hayden MR, Ferrario CM, Whaley-Connell A, Sowers JR: Nebivolol improves insulin sensitivity in the TGR(Ren2)27 rat. Metabolism 2011;60: 1757-1766.

-9 Zhou X, Ma L, Habibi J, Whaley-Connell A, Hayden MR, Tilmon RD, Brown AN, Kim JA, DeMarco VG, Sowers JR: Nebivolol improves diastolic dysfunction and myocardial remodeling through reductions in oxidative stress in the Zucker obese rat. Hypertension 2010;55:880-888.

10 Tavazzi L: Nebivolol for heart failure in the elderly. Expert Rev Cardiovasc Ther 2007;5:423-433.

11 Maffei A, Di Pardo A, Carangi R, Carullo P, Poulet R, Gentile MT, Vecchione C, Lembo G: Nebivolol induces nitric oxide release in the heart through inducible nitric oxide synthase activation. Hypertension 2007;50:652-656.

$\checkmark 12$ Aragón JP, Condit ME, Bhushan S, Predmore BL, Patel SS, Grinsfelder DB, Gundewar S, Jha S, Calvert JW, Barouch LA, Lavu M, Wright HM, Lefer DJ: Beta3-adrenoreceptor stimulation ameliorates myocardial ischemia-reperfusion injury via endothelial nitric oxide synthase and neuronal nitric oxide synthase activation. J Am Coll Cardiol 2011;58: 2683-2691.

-13 Rozec B, Erfanian M, Laurent K, Trochu JN, Gauthier C: Nebivolol, a vasodilating selective beta(1)-blocker, is a beta(3)-adrenoceptor agonist in the nonfailing transplanted human heart. J Am Coll Cardiol 2009;53:1532-1538.

14 Chen Z, Peng IC, Sun W, Su MI, Hsu PH, Fu Y, Zhu Y, DeFea K, Pan S, Tsai MD, Shyy JY: AMP-activated protein kinase functionally phosphorylates endothelial nitric oxide synthase Ser633. Circ Res 2009;104:496-505.

15 Hodis J, Vaclavíková R, Farghali H: Beta-3 agonist-induced lipolysis and nitric oxide production: relationship to PPARgamma agonist/antagonist and AMP kinase modulation. Gen Physiol Biophys 2011;30:90-99. 


\section{CardioRenal Medicine}

\begin{tabular}{l|l}
\hline \multicolumn{2}{l}{ Cardiorenal Med 2012;2:225-233 } \\
\hline DOI: 10.1159/000339565 & $\begin{array}{l}\text { @ 2012 S. Karger AG, Basel } \\
\text { www.karger.com/crm }\end{array}$ \\
Published online: July 24, 2012
\end{tabular}

Gul et al.: Regulation of Overnutrition-Induced Cardiac Inflammatory Mechanisms by Nebivolol

16 Pulakat L, DeMarco VG, Ardhanari S, Chockalingam A, Gul R, Whaley-Connell A, Sowers JR: Adaptive mechanisms to compensate for overnutrition-induced cardiovascular abnormalities. Am J Physiol Regul Integr Comp Physiol 2011; 301:R885-R895.

17 Buss SJ, Muenz S, Riffel JH, Malekar P, Hagenmueller M, Weiss CS, Bea F, Bekeredjian R, Schinke-Braun M, Izumo S, Katus HA, Hardt SE: Beneficial effects of mammalian target of rapamycin inhibition on left ventricular remodeling after myocardial infarction. J Am Coll Cardiol 2009;54:2435-2446.

18 Stephanou A, Brar BK, Scarabelli TM, Jonassen AK, Yellon DM, Marber MS, Knight RA, Latchman DS: Ischemiainduced STAT-1 expression and activation play a critical role in cardiomyocyte apoptosis. J Biol Chem 2000;275: $10002-10008$.

19 Kristof AS, Marks-Konczalik J, Billings E, Moss J: Stimulation of signal transducer and activator of transcription-1 (STAT1)-dependent gene transcription by lipopolysaccharide and interferon-gamma is regulated by mammalian target of rapamycin. J Biol Chem 2003;278:33637-33644.

20 Hoit BD: Echocardiographic characterization of the cardiovascular phenotype in rodent models. Toxicol Pathol 2006; 34:105-110.

-21 DeMarco VG, Johnson MS, Ma L, Pulakat L, Mugerfeld I, Hayden MR, Garro M, Knight W, Britton SL, Koch LG, Sowers JR: Overweight female rats selectively breed for low aerobic capacity exhibit increased myocardial fibrosis and diastolic dysfunction. Am J Physiol Heart Circ Physiol 2012;302:H1667-H1682.

22 Shackelford DB, Shaw RJ: The LKB1-AMPK pathway: metabolism and growth control in tumour suppression. Nat Rev Cancer 2009;9:563-575.

-23 Ananthakrishnan R, Hallam K, Li Q, Ramasamy R: JAK-STAT pathway in cardiac ischemic stress. Vascul Pharmacol 2005;43:353-356.

24 Shioi T, McMullen JR, Tarnavski O, Converso K, Sherwood MC, Manning WJ, Izumo S: Rapamycin attenuates loadinduced cardiac hypertrophy in mice. Circulation 2003;107:1664-1670.

25 Soesanto W, Lin HY, Hu E, Lefler S, Litwin SE, Sena S, Abel ED, Symons JD, Jalili T: Mammalian target of rapamycin is a critical regulator of cardiac hypertrophy in spontaneously hypertensive rats. Hypertension 2009;54:1321-1327.

-26 Khamzina L, Veilleux A, Bergeron S, Marette A: Increased activation of the mammalian target of rapamycin pathway in liver and skeletal muscle of obese rats: possible involvement in obesity-linked insulin resistance. Endocrinology 2005;146:1473-1481.

-27 Um SH, Frigerio F, Watanabe M, Picard F, Joaquin M, Sticker M, Fumagalli S, Allegrini PR, Kozma SC, Auwerx J, Thomas G: Absence of S6K1 protects against age- and diet-induced obesity while enhancing insulin sensitivity. Nature 2004;431:200-205.

28 Kim JA, Jang HJ, Martinez-Lemus LA, Sowers JR: Activation of mTOR/p70S6 kinase by ANG II inhibits insulinstimulated endothelial nitric oxide synthase and vasodilation. Am J Physiol Endocrinol Metab 2012;302:E201-E208.

-29 Beauloye C, Bertrand L, Horman S, Hue L: AMPK activation, a preventive therapeutic target in the transition from cardiac injury to heart failure. Cardiovasc Res 2011;90:224-233.

-30 Gundewar S, Calvert JW, Jha S, Toedt-Pingel I, Ji SY, Nunez D, Ramachandran A, Anaya-Cisneros M, Tian R, Lefer DJ: Activation of AMP-activated protein kinase by metformin improves left ventricular function and survival in heart failure. Circ Res 2009;104:403-411.

-31 Turdi S, Fan X, Li J, Zhao J, Huff AF, Du M, Ren J: AMP-activated protein kinase deficiency exacerbates aging-induced myocardial contractile dysfunction. Aging Cell 2010;9:592-606.

32 Westphal S, Perwitz N, Iwen KAH, Kraus D, Schick R, Fasshauer M, Klein J: Expression of ATRAP in adipocytes and negative regulation by $\beta$-adrenergic stimulation of JAK/STAT. Horm Metab Res 2008;40:165-171.

-33 Scarpace PJ, Zhang Y: Leptin resistance: a predisposing factor for diet-induced obesity. Am J Physiol Regul Integr Comp Physiol 2009;296:R493-R500. 